\title{
Crizotinib may be used in Lewis lung carcinoma: A novel use for crizotinib
}

\author{
PU XIA，WEN-FENG GOU，SHUANG ZHAO and HUA-CHUAN ZHENG \\ Department of Biochemistry and Molecular Biology, Institute of Pathology and Pathophysiology, \\ School of Basic Medical Science, China Medical University, Shenyang, Liaoning 110001, P.R. China
}

Received February 12, 2013; Accepted March 19, 2013

DOI: $10.3892 /$ or.2013.2424

\begin{abstract}
Lung cancer accounts for 13\% (1.6 million) of the total cases and 18\% (1.4 million) of the deaths in 2008. Crizotinib (PF-02341066) is identified as an ATP competitive small-molecular inhibitor for anaplastic lymphoma kinase (ALK). The US Food and Drug Administration (FDA) approved crizotinib to be used for the treatment of patients with locally advanced or metastatic ALK-positive NSCLC in 2011. In the present study, the side population (SP) and main population (MP) cells were obtained from Lewis lung carcinoma cells (LLC) and analyzed by DNA dye (Hoechst 33342) and flow cytometry. LLC SP and MP cells were confirmed as no ALK fusion gene by fluorescence in situ hybridization. The effects of crizotinib on LLC SP and MP cells both in vivo and in vitro were identified. Our results indicate that crizotinib can induce apoptosis and $G_{1}$ phase arrest in LLC MP cells. Crizotinib used in combination with verapamil can inhibit proliferation of LLC SP cells. Moreover, crizotinib decreased tumor size and weight and inhibited angiogenesis in established xenografted tumors. To analyze the signaling pathway involved, computer simulation, Affymetrix microarray analysis and western blot analysis were performed. In these assays, crizotinib was found to dock into Smad3 and activate the Smad signaling pathway. Overall, these studies demonstrate the antitumor activity of crizotinib in LLC cell line, and provide a novel use for crizotinib.
\end{abstract}

\section{Introduction}

Lung cancer was the most commonly diagnosed cancer as well as the leading cause of cancer death in males in 2008 globally. It was the fourth most commonly diagnosed cancer and the

Correspondence to: Dr Hua-Chuan Zheng, Department of Biochemistry and Molecular Biology, Institute of Pathology and Pathophysiology, School of Basic Medical Science, China Medical University, Shenyang, Liaoning 110001, P.R. China

E-mail: zheng_huachuan@hotmail.com

Key words: crizotinib, $\mathrm{G}_{1}$ phase arrest, apoptosis, Lewis lung carcinoma, anaplastic lymphoma kinase second leading cause of cancer death among females. Lung cancer accounted for 1.61 million new cases and 1.38 million deaths in 2008 alone, representing $12.7 \%$ of new cancers and $18.2 \%$ of cancer mortality (1).

Crizotinib (PF-02341066; Pfizer) was identified as an orally bioavailable, potent, ATP competitive small-molecular inhibitor of the catalytic activity of MET kinase $(2,3)$, and belongs to the 3-benzyloxy-2-aminopyridine series of kinase inhibitors (4). Crizotinib is highly selective for anaplastic lymphoma kinase (ALK) and c-Met kinases and acts by binding to the adenosine triphosphate (ATP) binding site of the ALK enzyme (5). Crizotinib entered into phase I clinical trial in 2006 as a highly selective MET inhibitor $(2,6)$. The ongoing phase II trial was designed for ALK-rearranged NSCLC patients who had more than one previous chemotherapy regimen (7). In phase I and II trials, crizotinib was shown to be highly active in patients with advanced ALK-positive NSCLC (8). Based on the phase I and II trial data, in August 2011 crizotinib was approved by the US Food and Drug Administration (FDA) for the treatment of patients with locally advanced or metastatic ALK-positive NSCLC.

Cancer stem cells (CSCs) may be responsible for the tumorigenesis and contribute to the resistance of cancer cells to therapeutic interventions $(9,10)$. Cancer stem cells have an ability to exclude fluorescent DNA-binding dye (Hoechst 33342) and resist Hoechst 33342 staining due to the ABCG2 (BCRP1) transporter (11). Other researchers have also designated the small subset of cells as 'side population (SP)' cells, which are a minor population of cells that has been identified in a variety of cancers and have many CSC-like properties $(12,13)$.

However, to the best of our knowledge, there is no evidence showed the effects of crizotinib on Lewis lung carcinoma. In our studies, we found the antitumor activities of crizotinib on LLC cells in vivo and in vitro. Crizotinib inducted apoptosis and $G_{1}$ arrest in LLC cells by activating the Smad signaling pathways.

\section{Materials and methods}

Cell culture. LLC cells were obtained from the American Type Culture Collection (ATCC, Bethesda, MD, USA) and grown in RPMI-1640 medium (HyClone, Logan, UT, USA) supplemented with $10 \%$ fetal bovine serum and antibiotics $(100 \mathrm{U} / \mathrm{ml}$ 
penicillin and $100 \mu \mathrm{g} / \mathrm{ml}$ streptomycin). Cells were maintained in a humidified cell incubator with $5 \% \mathrm{CO}_{2}$ at $37^{\circ} \mathrm{C}$.

Side population (SP) cell analysis. LLC cells were suspended at $1 \times 10^{6}$ cells $/ \mathrm{ml}$ and then incubated at $37^{\circ} \mathrm{C}$ for $60 \mathrm{~min}$ with $5 \mu \mathrm{g} / \mathrm{ml}$ Hoechst 33342 (Sigma Chemicals, St. Louis, MO, USA). The control cells were cultured in the presence of $500 \mu \mathrm{M}$ verapamil (Sigma). After incubation, $1 \mu \mathrm{g} / \mathrm{ml}$ propidium iodide (PI; KeyGen, Nanjing, China) was added to identify dead cells. Analysis and sorting of the SP cells was performed using a FACSVantage SE cytometer (BectonDickinson, San Jose, CA, USA). Hoechst 33342 was excited using a UV laser at $350 \mathrm{~nm}$ and fluorescence emission was measured at 402-446 $\mathrm{nm}$ for Hoechst blue and $640 \mathrm{~nm}$ for Hoechst red.

Fluorescent in situ hybridization. Fluorescent in situ hybridization is currently the gold standard method used in clinical trials to detect the ALK fusion gene, and it was the first FDA-approved method for detecting the ALK fusion (8). FISH was done on LCC SP and MP cells with the use of a break-apart probe specific to the ALK locus (Vysis LSI ALK Dual Color, Break Apart Rearrangement Probe; Abbott Molecular, Abbott Park, IL, USA) according to the manufacturer's instructions on LLC MP and SP cells. ALK-positive B cell was used as a positive control.

Colony formation assay. Cells were seeded at 200 cells/well in 24-well tissue culture plates. After $24 \mathrm{~h}$, cells were treated with various concentrations of crizotinib $(0$, 10, 20, 30 and $40 \mathrm{nM}$ for each). Three days after treatment, colonies were stained with $0.05 \%$ crystal violet containing $50 \%$ methanol and counted. The colonies were counted in 4 to 5 random fields for each of the duplicate samples by using a microscope at $\mathrm{x} 100$ magnification. The $\mathrm{IC}_{50}$ value for crizotinib was determined, and was applied to cells for $0,6,12,24$ and $48 \mathrm{~h}$.

Apoptosis assay. Apoptosis was determined using an apoptosis detection kit (KeyGen). Briefly, cells were collected, washed twice in ice-cold PBS, and then resuspended in binding buffer at a density of $1 \times 10^{6}$ cells $/ \mathrm{ml}$. The cells were simultaneously incubated with fluorescein-labeled Annexin $\mathrm{V}$ and propidium iodide (PI) for $20 \mathrm{~min}$, and flow cytometric (FCM) analysis performed using a FACSCalibur machine (Model FACSC 420, Baltimore, MD). Data were analyzed using CellQuest software (BD Biosciences, Baltimore, MD, USA), and the number of living cells (Annexin $\mathrm{V}^{-} / \mathrm{PI}^{-}$), early apoptotic cells (Annexin $\mathrm{V}^{+} / \mathrm{PI}^{-}$), damaged cells (Annexin $\mathrm{V}^{-} / \mathrm{PI}^{+}$) and necrotic cells (Annexin $\mathrm{V}^{+} / \mathrm{PI}^{+}$) was determined (14).

Measurement of caspase-3, -8 and -9 activities. Caspase activities were measured by colorimetric assay kit according to the manufacturer's instructions. After harvesting, cells were washed in ice-cold PBS and lysed; proteins were extracted and stored at $-80^{\circ} \mathrm{C}$ until use. Cell lysate $(20 \mu \mathrm{l})$ was added to a buffer containing a p-nitroaniline (pNA)-conjugated substrate (80 $\mu \mathrm{l}$ ) for caspase-3 (Ac-DEVD-pNA) (KeyGen; KGA203), -8 (Ac-IETD-pNA) (KeyGen; KGA302), or -9 (LEHD-pNA) (KeyGen; KGA402). Incubation was performed at $37^{\circ} \mathrm{C}$ with shaking (500 rpm for $1 \mathrm{~min}$ ) and then at room temperature for $2 \mathrm{~h}$. The released pNA in each well was measured using a plate-reading luminometer (Thermo Fisher Scientific, Beijing, China). Data were collected from three independent experiments.

Cell cycle analysis. Cells were collected, centrifuged at $1,500 \mathrm{x} \mathrm{g}$ for $5 \mathrm{~min}$, and the pellet was resuspended in $100 \mu \mathrm{l}$ PBS at a density of $1 \times 10^{6}$ cells $/ \mathrm{ml}$. Cold ethanol $(900 \mu \mathrm{l}$ of $70 \%$ ) was added to the mixture for $1 \mathrm{~h}$ on ice. Cells were collected by centrifugation at $1,500 \times \mathrm{g}$ for $5 \mathrm{~min}$. The pellet was then resuspended in $100 \mu \mathrm{l}$ PBS containing RNaseA $(0.2 \mathrm{mg} / \mathrm{ml})$ (Sigma) and left at room temperature for $30 \mathrm{~min}$. Cells were recovered by centrifugation and the pellets were resuspended in $350 \mu 1$ PBS containing $50 \mu \mathrm{g} / \mathrm{ml}$ PI (KeyGen) and analyzed by flow cytometry using a FACSCalibur machine (BD Biosciences).

Xenograft assays. All experiments with animals were performed according to the guidelines of the China Medical University Ethics Committee. NU/NU nude mice $(\mathrm{Crl}$ : NU-Foxn1nu) 6-8-weeks old were purchased from Charles River (Wilmington, MA, USA). SP ( $1 \times 10^{4}$ in $\left.200 \mu \mathrm{l}\right)$, MP cells $\left(1 \times 10^{6}\right.$ in $\left.200 \mu \mathrm{l}\right)$, or LLC cells $\left(1 \times 10^{5}\right.$ in $\left.200 \mu \mathrm{l}\right)$ were subcutaneously injected into the axilla of each mouse. After the tumor diameter reached 3-5 $\mathrm{mm}$, the mice were divided randomly into four groups (untreated, crizotinib, verapamil and crizotinib combined with verapamil) and received a $100 \mu 1$ intratumoral injection of PBS, crizotinib, verapamil, or crizotinib and verapamil. Two injections were administered at 10 a.m. and 4 p.m. every 2 days. Tumor growth was then monitored for 40 days. Every 10 days until the end of the experiment, one mouse from each group was randomly selected to be anesthetized, photographed and sacrificed. The tissues recovered were subjected to further analysis. For each tumor, measurements were made using calipers, and tumor volume was calculated as follows: length $\mathrm{x}$ width ${ }^{2} \mathrm{x} 0.52$ (15). Tumors were subsequently fixed in $4 \%$ paraformaldehyde for $24 \mathrm{~h}$, then embedded in paraffin.

Quantification of intratumoral microvessels. For immunohistochemical staining of CD31, endogenous peroxidase activity was blocked in $4 \mu \mathrm{m}$ tumor sections with $3 \%$ hydrogen peroxide for $30 \mathrm{~min}$. Antigen retrieval was performed in citrate buffer $(10 \mathrm{mM}, \mathrm{pH} 6.0)$ for $30 \mathrm{~min}$ at $95^{\circ} \mathrm{C}$ in a pressure cooker. CD31 antibodies (Sigma) were incubated with sections at 1:500 overnight at $4^{\circ} \mathrm{C}$. Sections were then incubated with a biotinylated secondary antibody for $60 \mathrm{~min}$ at room temperature, followed by incubation with a streptavidin horseradish peroxidase (HRP) complex (Beyotime, Beijing, China) for $60 \mathrm{~min}$ at room temperature. Bound antibody was visualized with 3,3'-diaminobenzidine tetrahydrochloride (DAB, Beyotime). Sections were also counterstained with hematoxylin (Beyotime). Microvessel density was detected using the method of Ivkovic-Kapicl et al (16). Regions of highest vessel density were located at low magnification (x40), then the number of vessels were counted at x200 magnification. Three high magnification fields were counted for each tumor section and the mean microvessel density value was recorded for each. Any individual endothelial cells, or endothelial cell 
Table I. The antibodies used in the western blot analysis.

\begin{tabular}{|c|c|c|c|}
\hline Protein & Producer & Catalog no. & Dilution \\
\hline ABCG2 & Abcam (Cambridge, UK) & $\mathrm{ab} 24114$ & $1: 200$ \\
\hline CD133 & & ab19898 & $1: 200$ \\
\hline P-Smad3 & Santa Cruz Biotechnology (Santa Cruz, CA, USA) & sc-130218 & $1: 200$ \\
\hline Smad3 & & sc-101154 & $1: 200$ \\
\hline P-Smad2 & & sc-135644 & $1: 100$ \\
\hline Smad2 & & sc-6200 & $1: 100$ \\
\hline Smad4 & & sc-7966 & $1: 200$ \\
\hline$\beta$-actin & & sc-47778 & $1: 1,000$ \\
\hline
\end{tabular}

cluster, that was clearly separated from adjacent microvessels was counted as a single microvessel.

Model of crizotinib bound to Smad3. The structure of Smad3 (PDB code: 1MK2) (17) with crystallographic resolutions of less than $3.0 \AA$, were retrieved from the Protein Data Bank (http://www.rcsb.org). The molecular structure of crizotinib (CID_11626560) was downloaded from PubChem Compound (http://www.ncbi.nlm.nih.gov/pccompound). Data were imported into the modeling software SYBYL-X 1.3 (Tripos International, St. Louis, MO, USA). All non-protein components such as water molecules, metal ions, and lipids were deleted and hydrogen atoms were added to the protein structures. The interaction of crizotinib and Smad 3 protein was analyzed by SYBYL-X 1.3.

$R T-P C R$. Total RNA was isolated from MP and SP cells using an RNeasy Mini kit (Biomed, Beijing, China). cDNA was reverse transcribed with $1 \mu \mathrm{g}$ of total RNA using a Takara Reverse Transcription kit (Takara Dalian, Dalian, China) and was amplified using the following primers. $C D 133$ primers were 5'-ACCGACTGAGACCCAACATC-3' (sense) and 5'-GG TGCTGTTCAGTTCTCCA-3' (antisense). ABCG2 primers were 5'-AGCTGCAAGGAAAGATCCAA-3' (sense) and 5'-TCCAGACACACCACGGATAA-3' (antisense). GAPDH primers were 5'-AGAAGGCTGGGGCTCATTTG-3' and (sense) and 5'-AGGGGCCATCCACAGTCTTC-3' (antisense) and used as an internal control. The PCR products were electrophoresed on a $1.5 \%$ agarose gel, and visualized by ethidium bromide staining under a UV imaging system (UVP, LLC; Upland, CA, USA).

Affymetrix microarray analysis. Microarray experiments were conducted according to standard protocols for Affymetrix Genome U133 Plus 2.0 arrays (Affymetrix, Inc., Santa Clara, CA, USA) (18). Briefly, using $1 \mu \mathrm{g}$ of total RNA, cDNA and biotinated cRNA synthesis was performed using the GeneChip expression 3' amplification reagents (one-cycle cDNA synthesis and IVT labeling) kits of Affymetrix following the manufacturer's protocols. Fragmented cRNA was applied to the hybridization and scanning of the array was performed following the manufacturer's protocols.

Antibodies and western blotting. Crude xenograft lysates were then centrifuged at $14,000 \times \mathrm{g}$ for $10 \mathrm{~min}$, and cleared lysates were collected and separated by $10 \%$ SDS-polyacrylamide gel electrophoresis and transferred to nitrocellulose membranes. Membranes were blocked in 5\% BSA-TBST then incubated with primary antibodies. Antibodies used in our study are summarized in Table I. The reaction was followed by probing with peroxidase-coupled secondary antibodies including anti-mouse $\mathrm{IgG}$, anti-rabbit $\mathrm{IgG}$, or anti-goat $\mathrm{IgG}$ antibodies at dilutions ranging from 1:1,000 to 1:2,000 (Amersham Biosciences, Needham, MA, USA), and binding results were visualized by enhanced chemiluminescence (Amersham Pharmacia, Piscataway, NJ, USA).

Statistical analysis. Each experiment was performed in triplicate. Statistical analysis was performed using one-tailed Student's t-test (unilateral and unpaired). Differences with a P-value $<0.05$ were considered to indicate a statistically significant result.

\section{Results}

Side population (SP) fraction and main population (MP) fraction in LLC show no ALK-rearrangement. LLC cells were labeled with Hoechst 33342 and analyzed by flow cytometry. We found that the SP cell fraction comprised $0.28 \%$ of the total cells, and that this population disappeared following treatment with the selective ABCG2 transporter inhibitor, verapamil (Fig. 1). The SP and MP of LLC cells were tested for ALK rearrangements by FISH analysis. A break-apart FISH probe has been used to detect the ALK fusion (Fig. 2A), and the probes are designed for the telomeric and centromeric sides of the break points. The terminal part of the der (3) harboring the 3' end of ALK showed red signal and loss of the 5' end of ALK showed green signal. SP and MP cells showed undetectable ALK rearrangement (Fig. 2C and D). In contrast, ALK rearrangement was readily detectable in an ALK-rearranged anaplastic large B cell lymphoma (Fig. 2B).

Crizotinib exposure inhibits proliferation and induces apoptosis and $G_{l}$ arrest in MP and SP cells. As shown in Fig. 3A, the inhibitory effects of crizotinib on MP cells and SP cells were determined by colony formation assay. $\mathrm{The} \mathrm{IC}_{50}$ value of crizotinib for MP cells was $21.3 \mathrm{nM}$. Of note, the SP cells showed no significant changes after crizotinib treatment. However, the SP cells showed a cell survival rate of $50.0 \pm 0.6 \%$ following a combined treatment of crizotinib (22.4 nM) and 

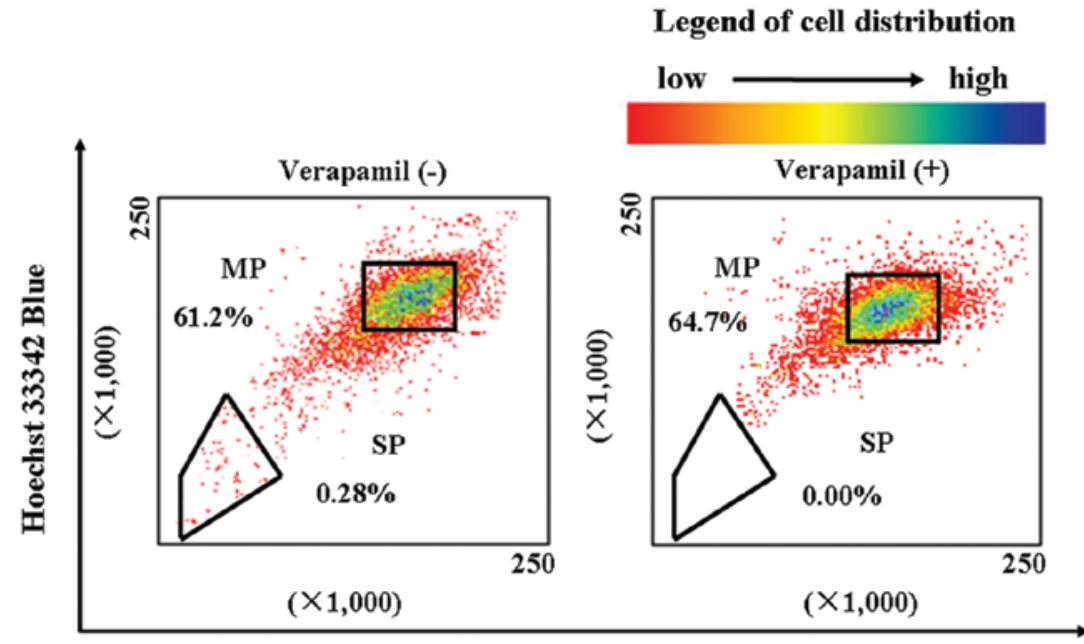

Hoechst 33342 Red

Figure 1. Identification of side population (SP) and main population (MP) cells in LLC cell lines. LLC cells $\left(1 \times 10^{6}\right.$ cells/ml) were cultured at $37^{\circ} \mathrm{C}$ for 60 min

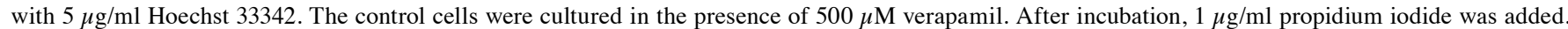
Analysis and sorting were performed on FACSVantage SE.
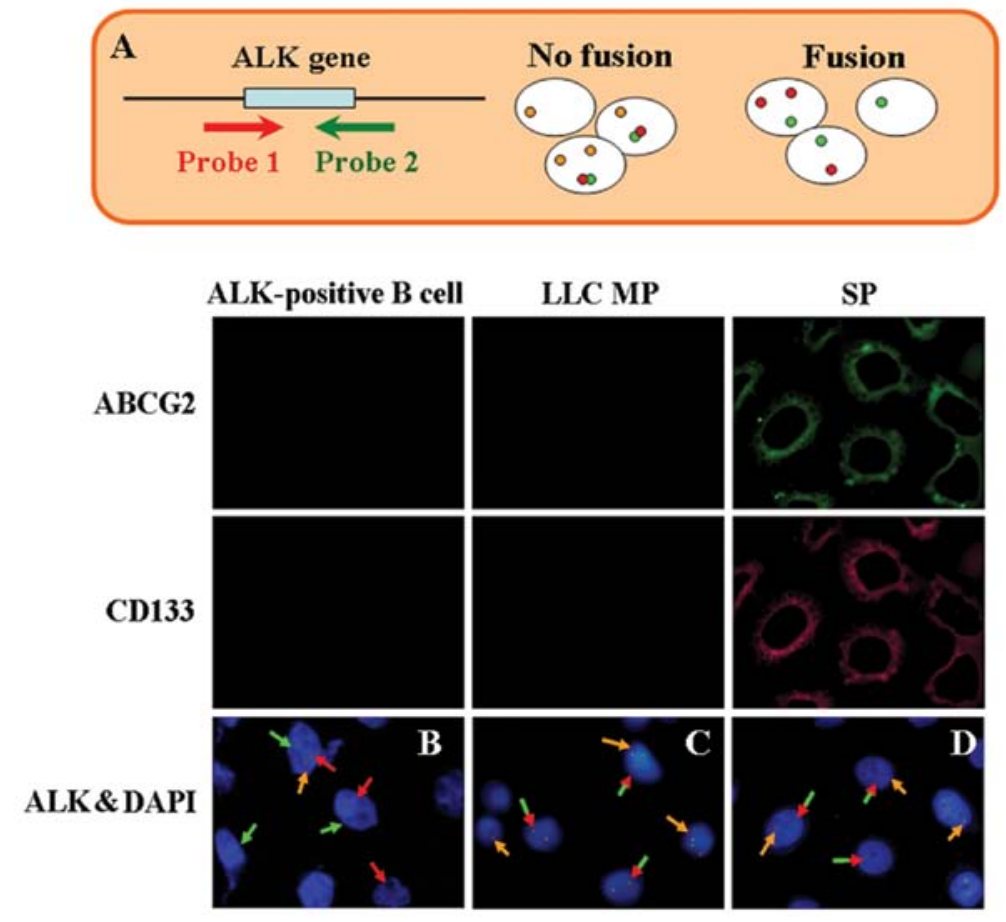

Figure 2. Fluorescent in situ hybridization method for ALK fusion detection. (A) The probes, which are labeled with different fluorescence, are designed at telomeric and centromeric sides between a breakpoint. (B) Representative FISH images of ALK-positive and (C and D) negative cells are displayed. When ALK is translocated, the signals are changed from merged yellow to single red and green. The expression and location of ABCG2 and CD133 proteins were also examined by immunofluorescence using indicated antibodies.

verapamil $(500 \mu \mathrm{M})$, compared with $105.3 \pm 0.4 \%$ survival of SP cells treated with crizotinib $(22.4 \mathrm{nM})$ alone (Fig. 3A, P<0.05). The growth curves obtained demonstrate that crizotinib inhibited the growth of SP and MP cells, and this inhibition was dependent on both concentration and time (Fig. 3A and B). In addition to the inhibitory effect on proliferation, crizotinib also induced apoptosis in the MP cells. The apoptotic ratio of MP cells exposed to $21.3 \mathrm{nM}$ crizotinib was $4.36 \pm 0.15 \%$ by using Annexin V and PI double staining, whereas $0.21 \pm 0.09 \%$ was observed in the untreated MP cells (Fig. 3C, $\mathrm{P}<0.05$ ). Similarly, SP cells after the combined treatment of crizotinib and verapamil showed a higher apoptotic ratio $(4.67 \pm 0.14 \%)$ compared with untreated SP cells $(0.19 \pm 0.05 \%)$ and SP cells after crizotinib treatment $(0.63 \pm 0.08 \%)$ (Fig. $3 \mathrm{C}, \mathrm{P}<0.05)$. Next, the effects of crizotinib on cell cycle progression were examined. As shown in Fig. 3D, MP cells treated with crizotinib and SP cells treated with crizotinib and verapamil were observed to arrest in the $G_{1}$ phase of the cell cycle. For 
Table II. Summary of Smad RNAs in LLC cell xenografts and SP cell xenografts

\begin{tabular}{|c|c|c|c|}
\hline \multicolumn{2}{|c|}{ LLC cell xenografts } & \multicolumn{2}{|c|}{ SP cell xenografts } \\
\hline RNA ID & $\mathrm{Ct}$ & RNA ID & $\mathrm{Ct}$ \\
\hline \multicolumn{4}{|c|}{ Untreated } \\
\hline $\mathrm{ABCG} 2$ & 0.014 & ABCG2 & -1.425 \\
\hline CD133 & 0.023 & CD133 & -2.993 \\
\hline Smad3 & 2.054 & Smad3 & 2.047 \\
\hline Smad2 & -1.534 & Smad2 & -1.556 \\
\hline Smad4 & 2.861 & Smad4 & 3.452 \\
\hline GAPDH & -2.245 & GAPDH & -2.131 \\
\hline \multicolumn{4}{|c|}{ Crizotinib } \\
\hline ABCG2 & a & ABCG2 & -1.367 \\
\hline CD133 & 0.024 & CD133 & -2.975 \\
\hline Smad3 & 2.391 & Smad3 & 2.889 \\
\hline Smad2 & -1.231 & Smad2 & -1.572 \\
\hline Smad4 & -3.884 & Smad4 & 3.425 \\
\hline GAPDH & -2.028 & GAPDH & -2.226 \\
\hline \multicolumn{4}{|c|}{ Verapamil } \\
\hline $\mathrm{ABCG} 2$ & 0.034 & ABCG2 & -1.352 \\
\hline CD133 & 0.045 & CD133 & -2.934 \\
\hline Smad3 & 2.196 & Smad3 & 2.717 \\
\hline Smad2 & -1.264 & $\mathrm{Smad} 2$ & -1.595 \\
\hline Smad4 & 2.885 & Smad4 & 3.314 \\
\hline GAPDH & -2.168 & GAPDH & -2.157 \\
\hline \multicolumn{4}{|c|}{ Crizotinib and verapamil } \\
\hline ABCG2 & 0.035 & ABCG2 & -1.453 \\
\hline CD133 & a & CD133 & -2.763 \\
\hline Smad3 & 2.201 & Smad3 & 2.624 \\
\hline Smad2 & -1.376 & Smad2 & -1.528 \\
\hline Smad4 & -3.874 & Smad4 & -3.642 \\
\hline GAPDH & -2.264 & GAPDH & -2.142 \\
\hline
\end{tabular}

${ }^{\mathrm{a} N o t}$ detected.

example, the percentages of MP cells in the $\mathrm{G}_{1}$ phase following treatment with crizotinib was $67.4 \pm 3.5 \%$ and $68.4 \pm 3.2 \%$ of SP cells after the combined treatment of crizotinib and verapamil, respectively $(\mathrm{P}<0.05)$. Furthermore, the activity of caspase-3, -8 and -9 was significantly increased in the crizotinib-treated MP cells and crizotinib and verapamil-treated SP cells (Fig. 3E, $\mathrm{P}<0.05)$. Verapamil showed no antitumor effects on MP and SP cells (Fig. 3, P>0.05).

Crizotinib inhibits tumor growth and angiogenesis in vivo. Tumorigenicity was examined using immune-deficient mice, into which SP or MP cells of LLC were subcutaneously transplanted. Nonsorted LLC cells formed xenografts in mice at $1 \times 10^{5}$ cells. Transplantation of $1 \times 10^{5} \mathrm{MP}$ cells consistently failed to form tumors in all mice $(n=5)$, while
$1 \times 10^{6} \mathrm{MP}$ cells showed tumor formation in one of five mice. The tumor volume of MP cell xenografts was smaller than that of SP cells. In contrast, transplantation of $1 \times 10^{4}$ SP cells produced tumors in all of five mice and the tumor volume were larger than MP group and LLC group (Fig. 4A). We next determined whether crizotinib displays antitumor properties in established xenograft tumor models. As shown in Fig. 4B, the tumor volume of crizotinib-treated LLC mice was 1.1to 3.2-fold less than untreated LLC mice $(\mathrm{P}<0.05)$. Tumor size was significantly decreased in the crizotinib-treated LLC groups $\left(225 \pm 29 \mathrm{~mm}^{3}\right)$ compared to the untreated group (PBS: $834 \pm 41 \mathrm{~mm}^{3}$ ) by 40 days after treatment. Similarly, tumor weight for the crizotinib-treated LLC group was also significantly reduced compared to the untreated LLC group (Fig. 4C, $\mathrm{P}<0.05$ ). We assessed intratumor microvessels by immunostaining for CD31 expression. Representative examples are shown in Fig. 4D. The blood vessel density of tumors from mice in the crizotinib-treated LLC group $\left(1.2 \pm 0.52\right.$ per $\left.\mathrm{mm}^{2}\right)$ was significantly reduced compared to the untreated LLC group $\left(4.6 \pm 0.64\right.$ per $\left.\mathrm{mm}^{2}\right)(\mathrm{P}<0.05)$. We also found that crizotinib and verapamil-treated SP mice displayed similar effects to crizotinib treated LLC mice. The tumor volume and weight of SP mice after the combined treatment of crizotinib and verapamil were significantly lower than that of untreated SP mice (Fig. 4B and $\mathrm{C}, \mathrm{P}<0.05)$. Consistent with in vitro results, verapamil showed no antitumor effects on LLC group and SP group in vivo (Fig. 4, $\mathrm{P}>0.05$ ).

Crizotinib binds to Smad3 and activates Smad4-dependent signaling. To explore the possible proteins that could interact with crizotinib, we applied the modeling software SYBYL-X 1.3 and found that crizotinib could dock into Smad3. Fig. 5B showed the binding sites between crizotinib and Smad3. To investigate whether crizotinib can play an anti-tumor role by activating Smad signaling pathway, we performed western blot analysis using antibodies that recognize phosphorylated, active Smad family members. Western blot analysis showed that phosphorylated levels of Smad2 and Smad3 significantly increased in crizotinib treated LLC cell xenografts and crizotinib and verapamil treated SP cell xenografts (Fig. 5D). Total protein levels of Smad 2 and Smad3 remained unchanged (Fig. 5D). In contrast, the total protein level of Smad4 significantly increased in LLC xenografts and SP xenografts after treatment (Fig. 5D). Interestingly, the level of Smad3 mRNA showed no changes in LLC xenografts and SP xenografts after treatment by using Affymetrix microarray analysis (Fig. 5A) (Table II). The results confirmed crizotinib activates Smad3 protein, but does not affect Smad3 transcription. The traits of LLC SP cells maintained in both in vitro and in vivo experiments were evidenced by detecting CD133 and ABCG2 expression (Fig. 5C).

\section{Discussion}

As noted in the introduction, crizotinib was approved by the US Food and Drug Administration (FDA) for the treatment of patients with locally advanced or metastatic ALK-positive NSCLC in August, 2011. However, no reports showed other applications and mechanisms of crizotinib in lung cancer 


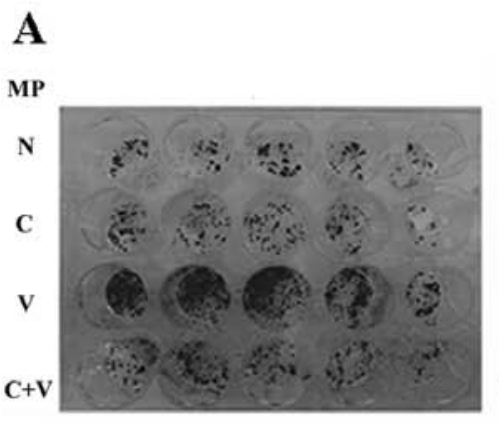

B

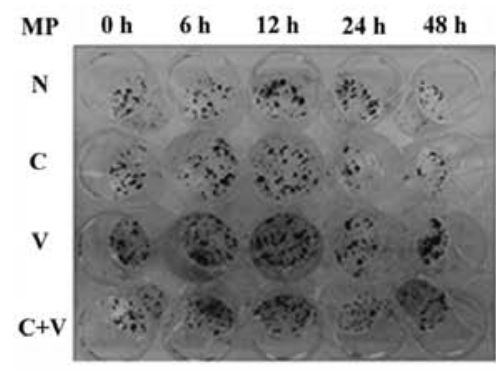

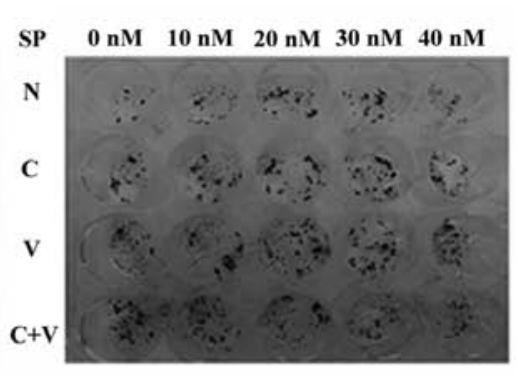
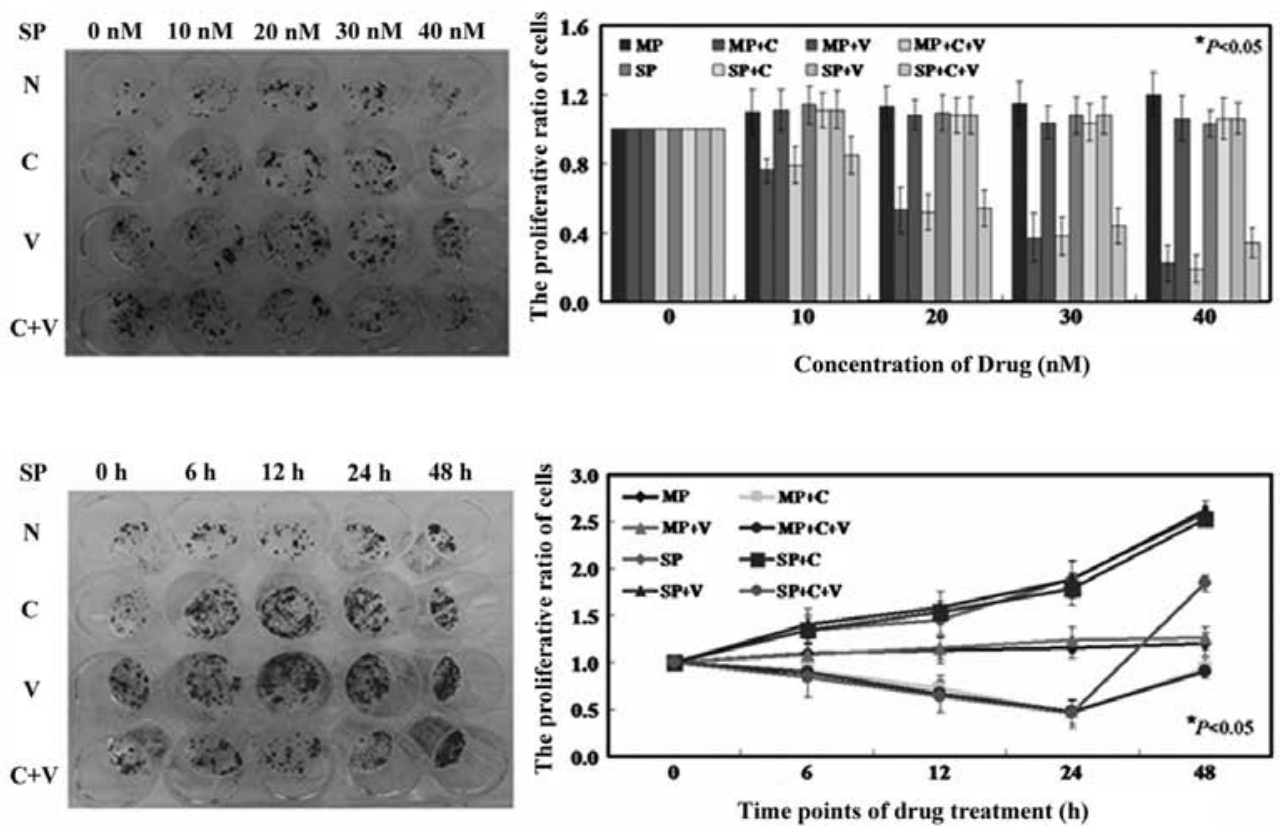
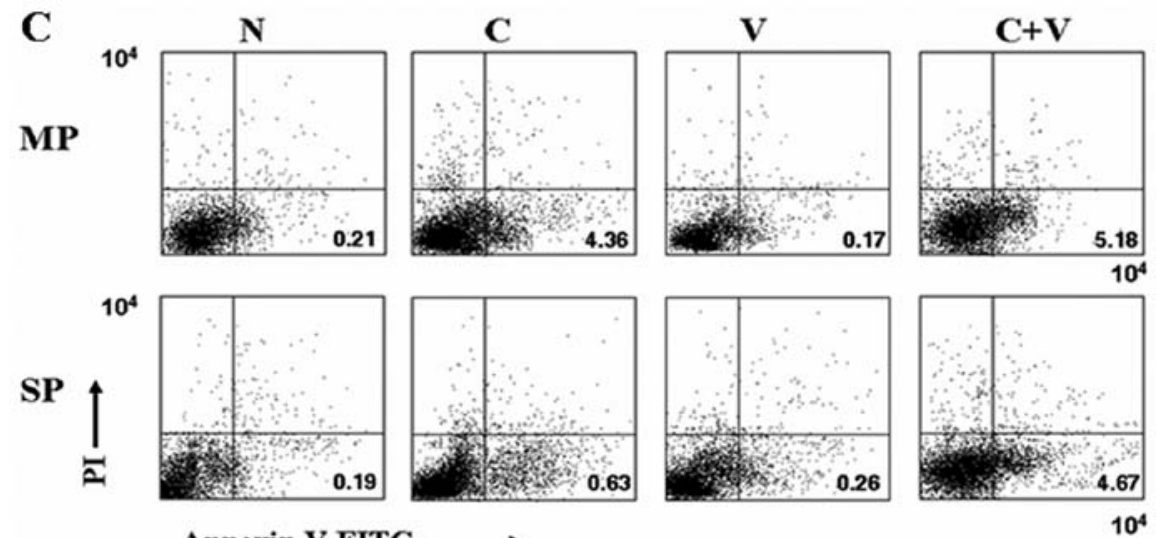

Annexin V-FITC

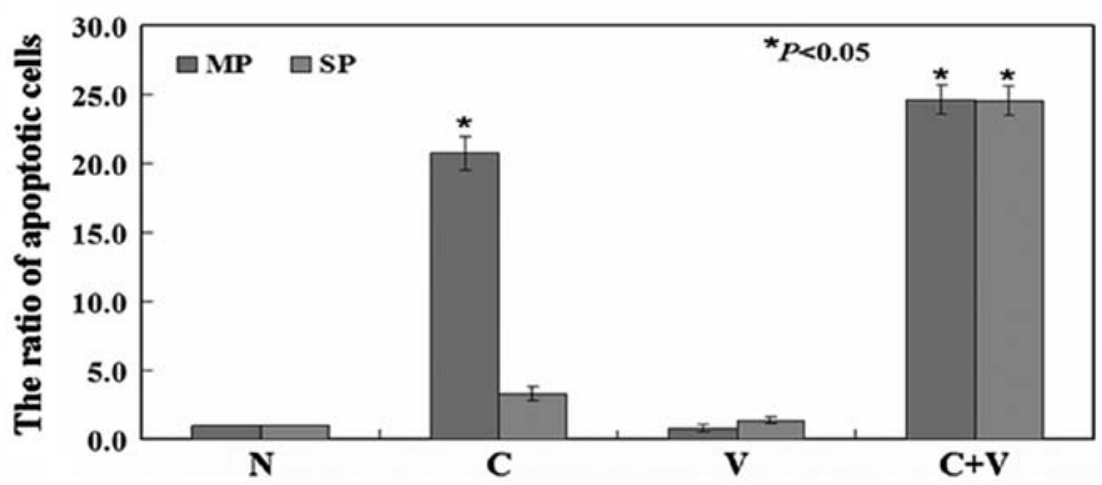

Figure 3. Antitumor activity of crizotinib detected in vitro. (A) Growth curves of LLC SP and MP cells treated with different concentrations of crizotinib with or without $500 \mu \mathrm{M}$ verapamil. (B) Growth curves of SP and MP cells treated with the $\mathrm{IC}_{50}$ concentration of crizotinib with or without $500 \mu \mathrm{M}$ verapamil at different time points. (C) The proportion of early apoptotic cells (e.g., FITC ${ }^{+} / \mathrm{PI}^{-}$cells) detected by flow cytometry following the double-staining of treated SP and MP cells with Annexin V/FITC and PI.

treatment. In the present study, we confirmed the antitumor effects of crizotinib on Lewis lung carcinoma in vitro and in vivo. Crizotinib in LLC MP cells decreased proliferation and induced G1 arrest and apoptosis. Additionally, crizotinib in LLC xenografted tumors inhibited tumor growth. We found intratumor microvessels were significantly reduced after treatment with crizotinib. However, crizotinib showed inhibitory effects on SP cells only combined with verapamil. SP cells are refractory to Hoechst 33342 dye-staining and certain drugs due to the ABCG2 (BCRP1) transporter $(11,19)$. The activity 
D
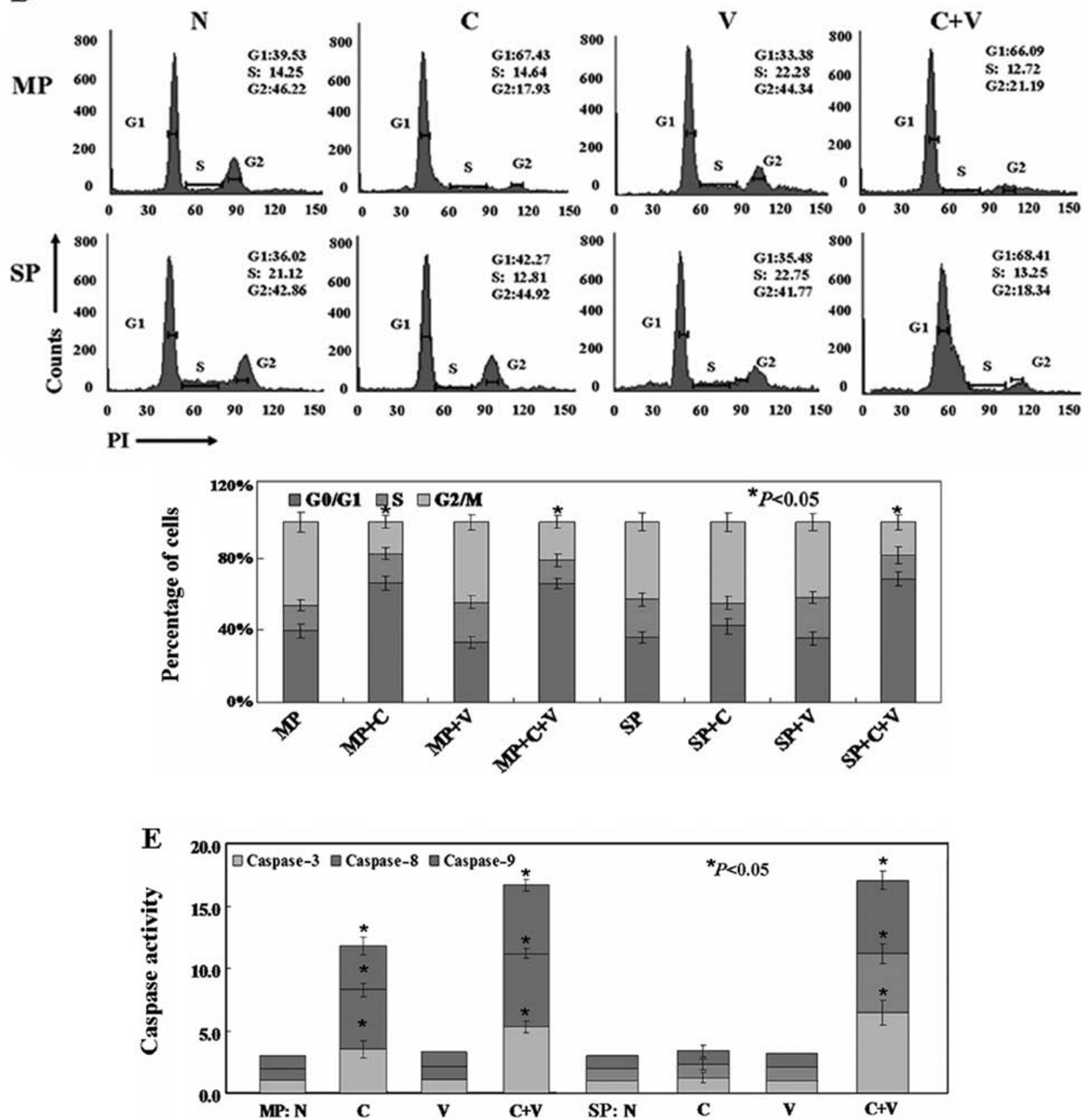

Figure 3. Continued. Antitumor activity of crizotinib detected in vitro. (D) Cells were stained with PI to analyze the cell cycle distribution of each cell type by flow cytometry. (E) The activity of caspase-3, -8 and -9 was detected in each group. Experiments were performed in triplicate and were repeated three times. $\mathrm{N}$, untreated cell; $\mathrm{C}$, cells treated with crizotinib; $\mathrm{V}$, cells treated with verapamil; $\mathrm{C}+\mathrm{V}$, cells treated with crizotinib and verapamil.

of the transporter is inhibited by verapamil, which results in the disappearance of the SP streak from the FACS plot $(20,21)$. Consistent with previous studies, we confirmed crizotinib was able to decrease the proliferation of SP cells when the activity of ABCG2 was inhibited by verapamil.

Several potential oncogenic drivers have been identified in NSCLC, such as EGFR, BRAF, KRAS, MET, HER2 and ALK (22-24). Crizotinib is a potent and selective ATP-competitive inhibitor of ALK receptor tyrosine kinases and oncogenic variants $(2,3,25)$. A recent study showed that crizotinib as a potential radiation-sensitizing agent in multiple established NSCLC cell lines with varying expression level of EML4-ALK (26). In the present study, we found another mechanism of crizotinib in LLC cells. To the best of our knowledge, no reports showed ALK-rearrangement in LCC cells. Currently several laboratories rely on FISH analysis of mitotic or interphase tumor nuclei and identify a 'split' hybridization signal to establish the presence of an ALK-rearrangement (27). We also confirmed no ALK-rearrangement in MP and SP of LLC cells by FISH analysis. The result indicated that crizotinib may play its antitumor role in LLC cells though other signaling pathways. The identification of candidate binding sites of proteins with crizotinib is the first step to detect the signaling pathway. In our previous study, we found crizotinib docked into Smad3 by using iGEMDOCK (version 2.1) and p-Smad3 was increased in A549 cells after crizotinib treat- 
A
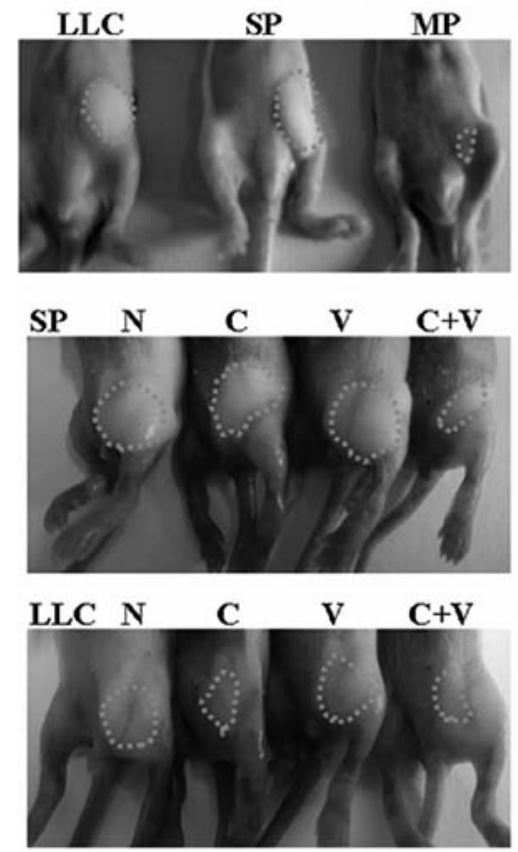
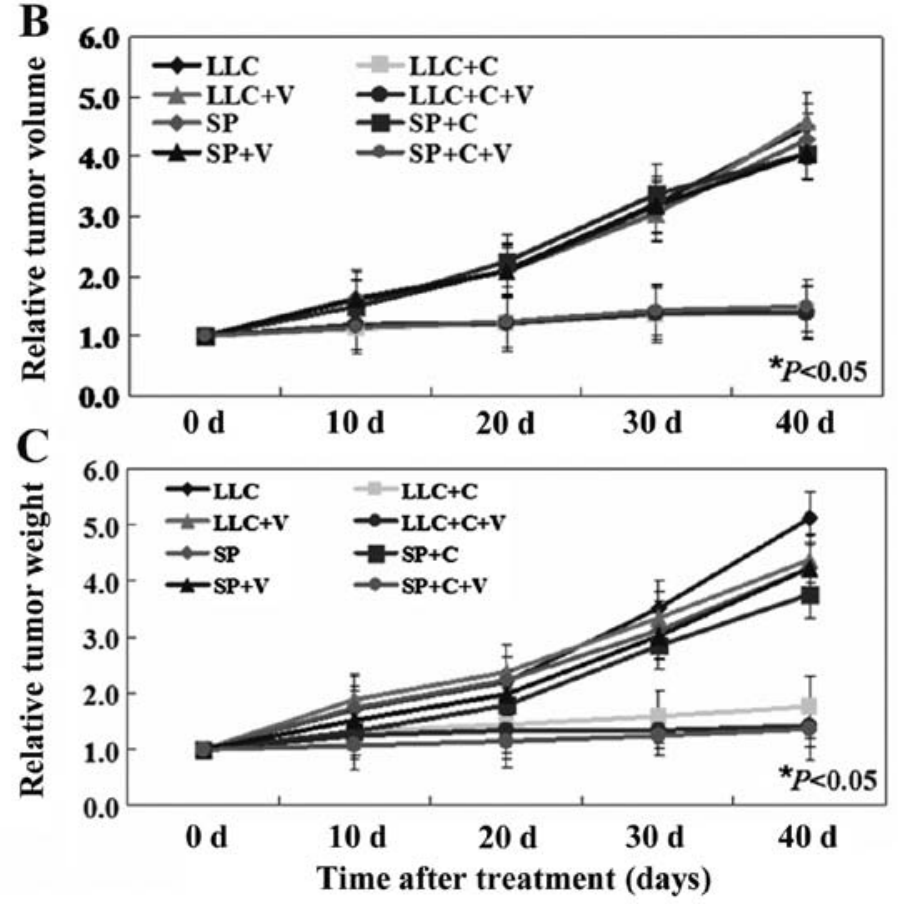

Time after treatment (days)
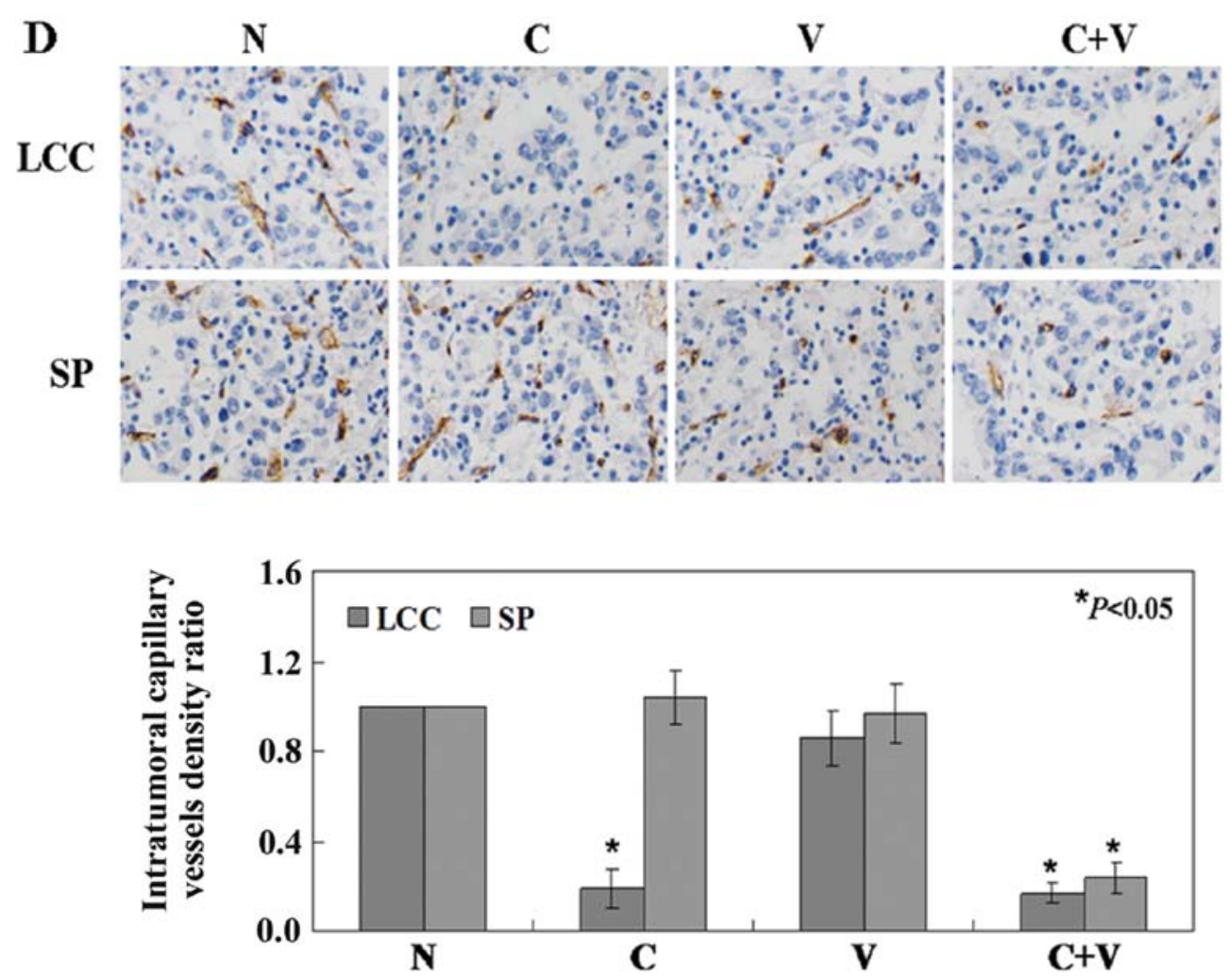

Figure 4. Crizotinib suppresses LLC cell tumor growth in vivo. (A-C). Tumor xenografts were established in nude mice with subcutaneous injections of LLC cells $\left(1 \times 10^{5} / 200 \mu 1\right)$, SP cells $\left(1 \times 10^{4} / 200 \mu \mathrm{l}\right)$ or MP cells $\left(1 \times 10^{6} / 200 \mu \mathrm{l}\right)$. After tumors reached $3-5 \mathrm{~mm}$ in diameter they were directly injected with PBS, crizotinib, verapamil, or both crizotinib and verapamil. Subsequently, tumors were resected from each group, and tumor volume and tumor weights were measured for each tumor group on days 10,20,30 and 40. (D) Immunohistochemical staining of tumor vessel endothelial cells using an anti-CD31 antibody. Bound antibody is detected with DAB and appears brown. Quantitation of vessel density ratios are provided below \pm standard deviation. Each experiment was performed in triplicate.

ment (28). In this study, we confirmed crizotinib could dock into the active center of Smad3 by SYBYL-X 1.3. Activated Smad3 (P-Smad3) was detected in LLC cells after crizotinib treatment and SP cells after crizotinib and verapamil treat- ment by western blot analysis. The downstream protein of Smad3, Smad2 was also activated and Smad4 expression was increased. Phosphorylated Smad2/3 could form complexes with Smad4 and translocate to the nucleus. The complexes 
A
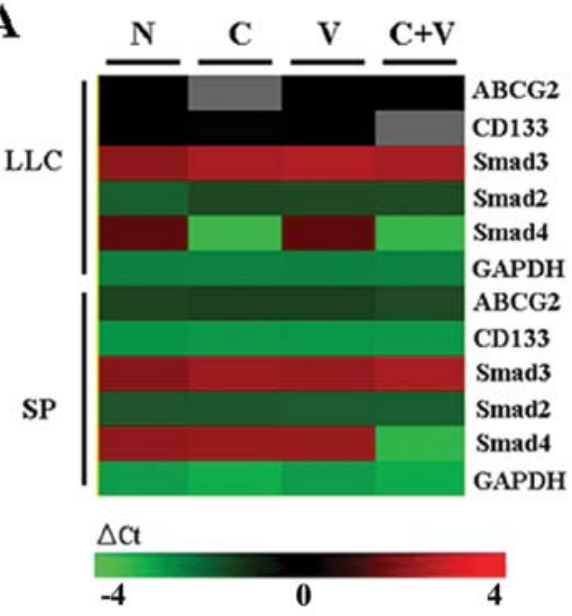

C

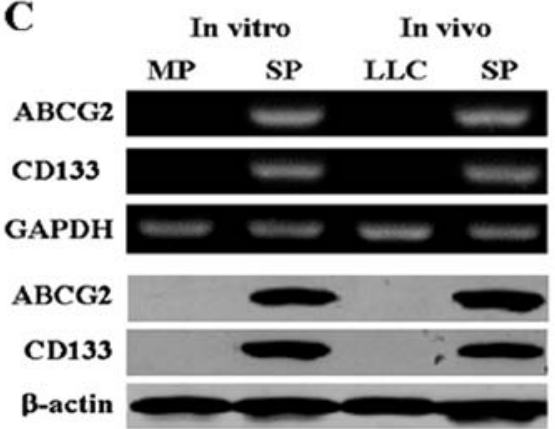

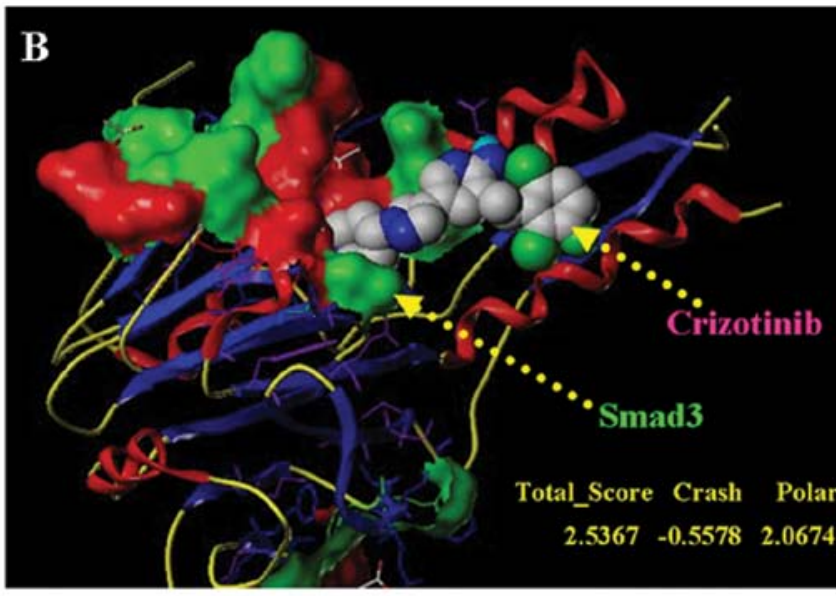

D

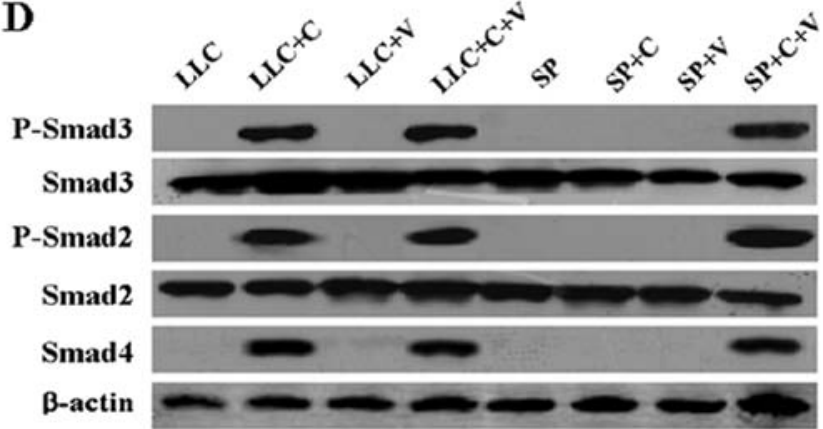

Figure 5. Effects of crizotinib on the Smad signaling pathway. (A) Heatmap of Smads RNA relative levels in LLC xenografts and SP xenografts. Each row indicates an RNA, each column indicates a sample. (B) Position of interaction sites in a model of crizotinib bound to the Smad3 domain. (C) Cellular protein was isolated from MP cells and SP cells, protein was isolated from LLC xenografts and SP xenografts, and the expression of ABCG2 and CD133 proteins were determined by western blot analysis using anti-ABCG2 and CD133 antibodies. $\beta$-actin was used as an internal control. (D) Western blot analysis was performed using Smad3 and p-Smad3, Smad2, p-Smad2 and Smad4. The level of p-Smad3, p-Smad2, and Smad4 proteins significantly increased in LLC xenografts and SP xenografts after treatment.

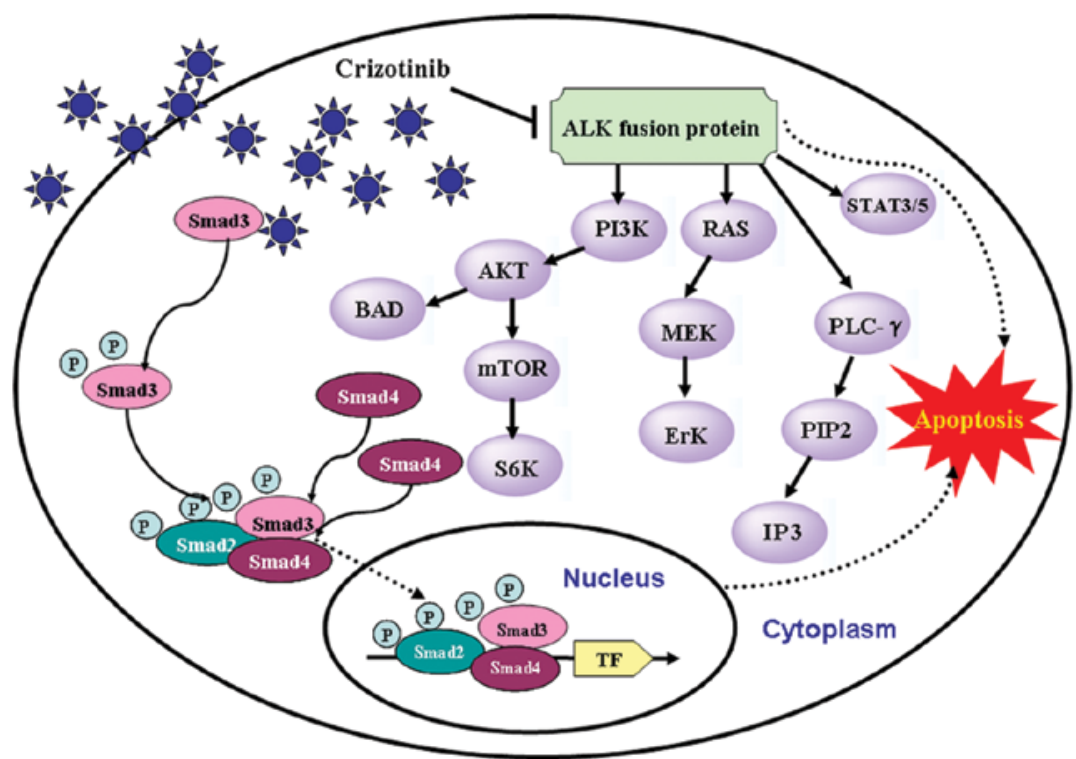

Figure 6. A proposed model for signaling pathways of crizotinib involved in the induction of apoptosis and $\mathrm{G}_{1}$ phase arrest in the LLC cells.

regulated the transcription of target genes by direct binding to specific DNA sequences $(29,30)$. Previous studies have demonstrated that Smad activation could induce apoptosis and cell cycle arrest (31-33). Consistent with these studies, we also found activation of Smad signaling could induce $\mathrm{G}_{1}$ arrest and apoptosis in LCC cells. 
Collectively, these studies are the first to determine the effects of crizotinib on Lewis lung carcinoma cells in vivo and in vitro. We demonstrate that crizotinib plays a tumor suppressor role in LLC cells through Smad signaling. These results provide a novel insight into possible therapeutic application of crizotinib.

\section{Acknowledgements}

We thank Miss Jing-Jing Wang for her valuable comments and excellent technical assistances.

\section{References}

1. Jemal A, Bray F, Center MM, et al: Global cancer statistics. CA Cancer J Clin 6: 69-90, 2011

2. Christensen JG, Zou HY, Arango ME, et al: Cytoreductive antitumor activity of PF-2341066, a novel inhibitor of anaplastic lymphoma kinase and c-Met, in experimental models of anaplastic large-cell lymphoma. Mol Cancer Ther 6: 3314-3322, 2007.

3. Zou HY, Li Q, Lee JH, et al: An orally available small-molecule inhibitor of c-Met, PF-2341066, exhibits cytoreductive antitumor efficacy through antiproliferative and antiangiogenic mechanisms. Cancer Res 67: 4408-4417, 2007.

4. Timofeevski SL, McTigue MA, Ryan K, et al: Enzymatic characterization of c-Met receptor tyrosine kinase oncogenic mutants and kinetic studies with aminopyridine and triazolopyrazine inhibitors. Biochemistry 48: 5339-5349, 2009.

5. Li Y, Ye X, Liu J, et al: Evaluation of EML4-ALK fusion proteins in non-small cell lung cancer using small molecule inhibitors. Neoplasia 13: 1-11, 2011.

6. Ou SH, Bazhenova L, Camidge DR, et al: Rapid and dramatic radiographic and clinical response to an ALK inhibitor (crizotinib, PF02341066) in an ALK translocation-positive patient with non-small cell lung cancer. J Thorac Oncol 5: 2044-2046, 2010.

7. Crinò L, Kim D, Riely GJ, et al: Initial phase II results with crizotinib in advanced ALK-positive non-small cell lung cancer (NSCLC): PROFILE 1005. J Clin Oncol 29: 7514, 2011.

8. Kwak EL, Bang YJ, Camidge DR, et al: Anaplastic lymphoma kinase inhibition in non-small-cell lung cancer. N Engl J Med 363: 1693-1703, 2010.

9. Klonisch $\mathrm{T}$, Wiechec E, Hombach-Klonisch S, et al: Cancer stem cell markers in common cancers - therapeutic implications. Trends Mol Med 14: 450-460, 2008.

10. Dingli D and Michor F: Successful therapy must eradicate cancer stem cells. Stem Cells 24: 2603-2610, 2006.

11. Kondo T, Setoguchi T and Taga T: Persistence of a small subpopulation of cancer stem-like cells in the C6 glioma cell line. Proc Natl Acad Sci USA 101: 781-786, 2004.

12. Wu C, Wei Q, Utomo V, et al: Side population cells isolated from mesenchymal neoplasms have tumor initiating potential. Cancer Res 67: 8216-8222, 2007.

13. Szotek PP, Pieretti-Vanmarcke R, Masiakos PT, et al: Ovarian cancer side population defines cells with stem cell-like characteristics and Mullerian Inhibiting Substance responsiveness. Proc Natl Acad Sci USA 103: 11154-11159, 2006.

14. Krysko DV, Vanden Berghe T, D'Herde K, et al: Apoptosis and necrosis: detection, discrimination and phagocytosis. Methods 44: 205-221, 2008.
15. Alessandri G, Filippeschi S, Sinibaldi P, et al: Influence of gangliosides on primary and metastatic neoplastic growth in human and murine cells. Cancer Res 47: 4243-4247, 1987.

16. Ivković-Kapicl T, Knelević-Usaj S, Panjković M, et al: Immunohistochemical analysis of angiogenesis in invasive ductal breast carcinoma with correlations to clinicopathological factor. Vojnosanit Pregl 63: 635-642, 2006 (In Serbian).

17. Qin BY, Lam SS, Correia JJ, et al: Smad3 allostery links TGF- $\beta$ receptor kinase activation to transcriptional control. Genes Dev 16: 1950-1963, 2002.

18. Martínez T and Pascual A: Gene expression profile in $\beta$-amyloidtreated SH-SY5Y neuroblastoma cells. Brain Res Bull 72: 225-231, 2007

19. Zillhardt M, Christensen JG and Lengyel E: An orally available small-molecule inhibitor of c-Met, PF-2341066, reduces tumor burden and metastasis in a preclinical model of ovarian cancer metastasis. Neoplasia 12: 1-10, 2010.

20. Tumati V, Kumar S, Yu L, et al: Effect of PF-02341066 and radiation on non-small cell lung cancer cells. Oncol Rep 29: 1094-1100, 2012

21. Hirschmann-Jax C, Foster AE, Wulf GG, et al: A distinct 'side population' of cells with high drug efflux capacity in human tumor cells. Proc Natl Acad Sci USA 101: 14228-14233, 2004.

22. Bronte G, Rizzo S, La Paglia L, et al: Driver mutations and differential sensitivity to targeted therapies: a new approach to the treatment of lung adenocarcinoma. Cancer Treat Rev 36 (Suppl 3): S21-S29, 2010.

23. Garber K: ALK, lung cancer, and personalized therapy: portent of the future? J Natl Cancer Inst 102: 672-675, 2010.

24. Janku F, Stewart DJ and Kurzrock R: Targeted therapy in nonsmall-cell lung cancer - is it becoming a reality? Nat Rev Clin Oncol 7: 401-414, 2010

25. Challen GA and Little MH: A side order of stem cells: the SP phenotype. Stem Cells 24: 3-12, 2006.

26. Hadnagy A, Gaboury L, Beaulieu R, et al: SP analysis may be used to identify cancer stem cell populations. Exp Cell Res 312: 3701-3710, 2006

27. Shaw AT, Yeap BY, Mino-Kenudson M, et al: Clinical features and outcome of patients with non-small-cell lung cancer who harbor EML4-ALK. J Clin Oncol 27: 4247-4253, 2009.

28. Xia P, Mou FF and Wang LW: Predictive role of computer simulation in assessing signaling pathways of crizotinib-treated A549 lung cancer cells. Asian Pac J Cancer Prev 13: 3119-3121, 2012.

29. Jacob D, Davis J, Zhu H, et al: Suppressing orthotopic pancreatic tumor growth with a fiber-modified adenovector expressing the TRAIL gene from the human telomerase reverse transcriptase promoter. Clin Cancer Res 10: 3535-3541, 2004.

30. Zhu H, Zhang L, Huang X, et al: Overcoming acquired resistance to TRAIL by chemotherapeutic agents and calpain inhibitor I through distinct mechanisms. Mol Ther 9: 666-673, 2004.

31. Grau AM, Zhang L, Wang W, et al: Induction of p21waf1 expression and growth inhibition by transforming growth factor $\beta$ involve the tumor suppressor gene DPC4 in human pancreatic adenocarcinoma cells. Cancer Res 57: 3929-3934, 1997.

32. Guo Y and Kyprianou N: Overexpression of transforming growth factor (TGF) $\beta 1$ type II receptor restores TGF- $\beta 1$ sensitivity and signaling in human prostate cancer cells. Cell Growth Differ 9: 185-193, 1998.

33. Tang MR, Wang YX, Guo S, et al: CSMD1 exhibits antitumor activity in A375 melanoma cells through activation of the Smad pathway. Apoptosis 17: 927-937, 2012. 